\title{
HÍBRIDOS DE AMOREIRA ADUBADOS COM MATÉRIA ORGÂNICA E GESSO AGRÍCOLA NA PRODUÇÃO DE BICHO-DA-SEDA
}

\author{
Nilton Cezar Bellizzi ${ }^{1,4 *}$; Luís Carlos Marchini²; Roque Takahashi ${ }^{3}$ \\ ${ }^{1}$ Unid. de Jardim - UEMS, Av. 11 de Dezembro s/n - CEP: 79240-000 - Jardim, MS. \\ ${ }_{3}^{2}$ Depto. de Entomologia, Fitopatologia e Zoologia Agrícola - USP/ESALQ, C.P. 9 - CEP: 13418-900 - Piracicaba, SP. \\ ${ }^{3}$ Depto. de Zootecnia - UNESP/FCAV, Via de Acesso Prof. Paulo D. Castellane, Km 5 - CEP: 14870-000 - \\ Jaboticabal, SP. \\ ${ }^{4}$ Bolsista CNPq. \\ *Autor correspondente <ncbellizzi@bol.com.br.>
}

RESUMO: A variedade de amoreira e a nutrição da mesma são fatores determinantes na produção de massa verde pela planta, no desenvolvimento do bicho-da-seda e na sua produção dos casulos. Este trabalho teve como objetivo avaliar o efeito da matéria orgânica ( $2 \mathrm{~kg}$ de esterco de galinha/planta) e matéria orgânica associada ao gesso agrícola ( $2 \mathrm{~kg}$ de esterco de galinha/planta $+250 \mathrm{~g}$ de gesso agrícola/ planta) em três híbridos de amoreira, IZ 64, IZ 19/13 e IZ 56/4, sobre a produção de folhas e ramos da amoreira, peso e teor líquido de seda dos casulos do bicho-da-seda. O híbrido IZ 56/4 e a adubação com matéria orgânica associada ao gesso agrícola proporcionaram as melhores produções de folhas e de ramos pela amoreira, influenciando positivamente no peso médio dos casulos do bicho da seda e no teor líquido de seda dos mesmos.

Palavras-chave: Morus sp., Bombyx mori, adubação orgânica, gesso agrícola

\section{MULBERRY HYBRIDS FERTILIZED WITH ORGANIC MATTER AND GYPSUM ON SILKWORM PRODUCTION}

\begin{abstract}
Mulberry variety and nutrition are determining factors for plant yield and the development of silkworm cocoons. To evaluate the effects of organic matter $(2 \mathrm{~kg}$ of chicken manure/plant) and organic matter plus gypsum ( $2 \mathrm{~kg}$ of chicken manure/plant $+250 \mathrm{~g}$ of gypsum) on three mulberry hybrids, IZ 64; IZ 19/13 and IZ 56/4, plant yield (leaves and branches), cocoon weight and net silk content in the cocoons were measured. Both the hybrid IZ 56/4 and the fertilization with organic matter plus gypsum resulted in higher leave and branche production in relation to other factors studied, therefore positively influencing in the weight and net silk level of the cocoons.
\end{abstract}

Key words: Morus sp., Bombyx mori, organic fertilization, gypsum

\section{INTRODUÇÃO}

Alguns fatores influenciam grandemente a criação do bicho-da-seda, e sem dúvida os que mais interferem são aqueles relacionados com a amoreira. Entre eles a variedade de amoreira bem como a nutrição são fatores determinantes na produção de massa verde, no desenvolvimento do inseto e na produção dos casulos.

Os primeiros trabalhos de pesquisa envolvendo cultivares de amoreira no Brasil, utilizaram variedades como: Calabresa, Fernão Dias, Lopes Lins, Paduana, Moretiana e Catânia Paulista (Rubia, 1964; Rubia \& Abramides, 1965; Rubia et al., 1966; Paolieri \& Frota, 1970) quando concluíram existir diferenças nas produções de folhas da amoreira e de casulos do bichoda-seda. Estes resultados, sem dúvida, geraram a perspectiva de encontrar cultivares mais produtivos, a fim de possibilitar maiores compensações aos que se dedicam a Sericicultura.

Comparando a produtividade de oito híbridos, com a variedade Calabresa, Fonseca et al. (1994) concluíram que o híbrido IZ 56/4 produziu 20416 kg de folhas/ha/ano, o IZ 19/13 produziu $17821 \mathrm{~kg}$ de folhas/ha/ano e a variedade Calabresa $8651 \mathrm{~kg}$ de folhas/ha/ano. O efeito destes híbridos na produção de casulos foi: IZ 56/4 de $795 \mathrm{~kg}$ de casulos/ha/ano, IZ $19 / 13$ de $696 \mathrm{~kg}$ de casulos/ha/ano e a Calabresa de $338 \mathrm{~kg}$ de casulos/ha/ano. Os autores mostraram que os híbridos estudados são muito superiores a variedade Calabresa, que é uma das mais utilizadas nos amoreirais e que a substituição desta variedade por um destes híbridos, poderia aumentar a produtividade da sericicultura.

Os benefícios da adubação orgânica são enumerados por diversos autores (Abreu \& Abramides, 1976; Fonseca \& Fonseca, 1988; Takahashi, 1994), atuando na absorção de minerais, complementando a adubação química, facilitando a penetração das raízes, diminuindo a erosão, permitindo melhor retenção de água no solo, maior arejamento, além do que também promovem o desenvolvimento de microorganismos imprescindíveis ao solo. Dentre todas as fontes de fertilizantes orgânicos, o esterco de galinha é o mais utilizado, proporcionando ótimos resultados à amoreira. 
Pesquisando os seguintes tratamentos na amoreira (variedade Yamada): $T_{1}=$ Testemunha (sem nenhuma adubação); $\mathrm{T}_{2}=\mathrm{N}, \mathrm{P}$ e K; $\mathrm{T}_{3}=$ Micronutrientes (Fe, Zn, Mn, B, Cu e Mo); $\mathrm{T}_{4}=$ Calcário; $\mathrm{T}_{5}=$ Calcário + NPK; $\mathrm{T}_{6}=$ Calcário + Micronutrientes; $\mathrm{T}_{7}=$ Gesso agrícola; $\mathrm{T}_{8}=$ Gesso agrícola $+\mathrm{NPK} ; \mathrm{T}_{9}=$ Gesso agrícola + Micronutrientes, Bellizzi (1997) concluiu que a aplicação de gesso agrícola $+\operatorname{NPK}\left(\mathrm{T}_{8}\right)$ apresentou melhores produções de folhas e ramos/planta além de proporcionar maior produção de casulos do bicho-daseda, podendo ser utilizado para aumentar a produtividade da sericicultura.

Ao estudar o efeito da adubação nitrogenada no desenvolvimento do bicho-da-seda Gomide \& Takahashi (1987) observaram que as larvas alimentadas com folhas de amoreira adubada com $200 \mathrm{~g}$ de sulfato de amônio, parcelados em três vezes, produziram casulos estatisticamente mais pesados $(1,39 \mathrm{~g})$ do que os mesmos $200 \mathrm{~g}$ de sulfato de amônio incorporados de uma única vez $(1,17 \mathrm{~g})$, logo após a poda da amoreira.

Neste trabalho estudaram-se os efeitos da matéria orgânica e sua associação com gesso agrícola na produção de massa verde dos híbridos de amoreira IZ 64, IZ 19/13 e IZ 56/4 e seus reflexos na produção de casulos pelo bicho-da-seda (Bombyx mori, L.).

\section{MATERIAL E MÉTODOS}

A pesquisa foi desenvolvida no Setor de Sericicultura do Departamento de Zootecnia da FCAV/ UNESP durante os meses de outubro de 1998 a junho de 1999. A área experimental situa-se em altitude de 595 m, latitude de 2115'22" S e 4818'58" W Gr. de longitude, apresentando um clima subtropical temperado, com verão quente/úmido e inverno seco (Cwa).

A temperatura máxima, mínima e média e precipitação pluviométrica no período do experimento estão registrados na TABELA 1.

$O$ amoreiral estudado encontrava-se em solo com as seguintes características: Latossolo Vermelho Escuro, de textura média, classificado pela $7^{\text {a }}$ Aproximação Americana como Typic Haplasthoxc, cuja análise química apresentou como resultados: $\mathrm{pH}\left(\mathrm{CaCl}_{2}\right.$ $0,01 \mathrm{M})=4,5 ; \mathrm{M} . \mathrm{O}=27 \mathrm{~g} \mathrm{ha}^{-1} ; \mathrm{P}=8 \mathrm{mg} \mathrm{dm} \mathrm{m}^{3} ; \mathrm{K}=3,1^{2}$ $\mathrm{mmol}_{\mathrm{c}} \mathrm{dm}^{-3} ; \mathrm{Ca}=12 \mathrm{mmol}_{\mathrm{c}} \mathrm{dm}^{-3} ; \mathrm{Mg}=5 \mathrm{mmol}_{\mathrm{c}} \mathrm{dm}^{-3}$; $\mathrm{H}+\mathrm{Al}=46 \mathrm{mmol}_{\mathrm{c}} \mathrm{dm}^{-3} ; \mathrm{SB}=22,1 \mathrm{mmol}_{\mathrm{c}} \mathrm{dm}^{-3} ; \mathrm{T}^{\mathrm{c}}=66,1$ $\mathrm{mmol}_{\mathrm{c}} \mathrm{dm}^{-3}$ e V $=30 \%$.

A fonte de matéria orgânica foi o esterco de galinha poedeira, adquirido na própria FCAV/UNESP, que apresentou a seguinte análise química: $\mathrm{pH}\left(\mathrm{CaCl}_{2} 0,01\right.$ mol L-1) $=7,1$; umidade total $=5,47 \%$; M.O. total $=$ $27,81 \%$; M.O. compostável $=22,09 \%$; M.O. resistente à compostagem $=5,72 \% ; \mathrm{C}$ total $=15,44 \% ; \mathrm{C}$ orgânico $=$ $12,27 \%$; resíduo mineral total $=72,19 \%$; resíduo mineral insolúvel $=35,05 \%$; resíduo mineral solúvel $=37,14 \%$; $\mathrm{N}$ total $=1,65 \% ; \mathrm{P}\left(\mathrm{P}_{2} \mathrm{O}_{5}\right)$ total $=3,66 \% ; \mathrm{K}\left(\mathrm{K}_{2} \mathrm{O}\right)$ total $=$ $2,15 \% ; \mathrm{Ca}$ total $=7,83 \% ; \mathrm{Mg}$ total $=0,58 \% ; \mathrm{S}$ total $=$
$0,28 \%$; relação $\mathrm{C} / \mathrm{N}(\mathrm{C}$ total $/ \mathrm{N}$ total $)=9 / 1$; relação $\mathrm{C} / \mathrm{N}$ $(\mathrm{C}$ orgânico/ $\mathrm{N}$ total $)=7 / 1 ; \mathrm{Cu}$ total $=166 \mathrm{mg} \mathrm{kg}^{-1} ; \mathrm{Mn}$ total $=709 \mathrm{mg} \mathrm{kg}^{-1} ; \mathrm{Zn}$ total $=248 \mathrm{mg} \mathrm{kg}^{-1} ; \mathrm{Fe}$ total $=$ $26491 \mathrm{mg} \mathrm{kg}^{-1}$ e $\mathrm{Na}$ total $=2411 \mathrm{mg} \mathrm{kg}^{-1}$. O gesso agrícola apresentou: Umidade total $=30,92 \%$; $\mathrm{S}$ total $=$ $15,98 \%$ e Ca total $=18,88 \%$.

Foram desenvolvidos 2 ensaios e em cada ensaio duas etapas, a primeira etapa iniciou com adubação da amoreira e terminou com a colheita das folhas para análise, a segunda etapa iniciou com a eclosão das lagartas do bicho-da-seda e terminou com o colheita dos casulos. No $1^{\circ}$ ensaio, a primeira fase foi de outubro/1998 a janeiro/1999, a segunda fase foi de janeiro a fevereiro de 1999 . No $2^{\circ}$ ensaio, a primeira fase que durou de fevereiro a maio de 1999 e a segunda fase iniciou em maio e terminou em junho de 1999.

Em cada ensaio foram realizadas adubações com matéria orgânica, de acordo com o tratamento, seguindo a recomendação de Takahashi (1994). O cálculo da dose de gesso seguiu a recomendação de Sousa et al. (1995): $250 \mathrm{~g}$ de gesso/planta, de acordo com a textura do solo.

As plantas utilizadas no experimento foram os híbridos IZ 64, IZ 19/13 e IZ 56/4, plantados em julho 1996 em espaçamento de 2,6 m entre linhas e 0,60 m entre plantas. Cada híbrido recebeu os seguintes tratamentos: $T_{1}=$ Testemunha absoluta (sem adubação); $\mathrm{T}_{2}=$ Adubação orgânica (2 kg de esterco de galinha/ planta) e $\mathrm{T}_{3}=$ Adubação orgânica com esterco de galinha associado ao gesso agrícola (2 kg de esterco de galinha/ planta $+250 \mathrm{~g}$ de gesso agrícola/planta).

As lagartas de bicho-da-seda utilizadas no experimento foram híbridos comerciais, adquiridos da Fiação de Seda Bratac S/A na forma de ovos, que após a eclosão das lagartas foram criadas até o final do $2^{\circ}$ ínstar em uma sala climatizada medindo $4,0 \times 5,0 \mathrm{~m}$ e pé direito de $3,0 \mathrm{~m}$, construída em alvenaria, com forro de laje, coberta com telhas de barro tipo francesa e piso de concreto liso. A temperatura média no interior da sala foi controlada através de ar condicionado e humidificador, mantendo em $25 \pm 1^{\circ} \mathrm{C}$ com $90 \pm 10 \%$ de UR.

Após a ecdise para o $3^{\circ}$ ínstar até a colheita do casulo, as lagartas foram criadas em sirgaria, medindo $13,0 \times 8,0 \mathrm{~m}$ e pé direito de $3,0 \mathrm{~m}$, construída em alvenaria, coberta com telhas de barro tipo francesa $e$ piso de concreto liso.

O manejo da alimentação, em todos os ínstares, foi feito através de cinco alimentações diárias: 7:30, 10:30, 13:30, 16:30 e 19:30 horas, com folhas a vontade.

$O$ delineamento experimental obedeceu o esquema de Delineamento em Blocos Casualizados (D.B.C.), no esquema fatorial $3 \times 3$, onde foram testados os efeitos de três adubações em três híbridos com cinco repetições, sendo utilizadas 10 plantas/parcela. Os resultados obtidos nos dois ensaios foram analisados pelo SAS (Statistical Analysis of System). A análise conjunta refere-se a realizada com dados dos dois ensaios. 
TABELA 1 - Médias mensais de temperatura máxima, mínima, média e precipitação pluviométrica na FCAVJ/UNESP em Jaboticabal - SP durante o período experimental (outubro/98 a junho/99).

\begin{tabular}{|c|c|c|c|c|}
\hline \multirow{2}{*}{ Mês } & \multicolumn{3}{|c|}{ Temperatura } & \multirow{2}{*}{$\begin{array}{l}\text { Precipitação } \\
\text { Pluvial }\end{array}$} \\
\hline & Máxima & Mínima & Média & \\
\hline & ------------------- & $-{ }^{\circ} \mathrm{C}-$ & ----------------- & -------- mm \\
\hline Outubro - 98 & 30,0 & 18,2 & 23,2 & 153,0 \\
\hline Novembro - 98 & 31,2 & 18,2 & 24,2 & 88,6 \\
\hline Dezembro - 98 & 30,6 & 19,9 & 24,5 & 324,7 \\
\hline Janeiro - 99 & 31,1 & 20,5 & 24,6 & 415,9 \\
\hline Fevereiro - 99 & 31,2 & 20,0 & 24,3 & 375,4 \\
\hline Março - 99 & 31,1 & 19,4 & 24,1 & 115,9 \\
\hline Abril - 99 & 29,7 & 16,1 & 21,9 & 107,4 \\
\hline Maio - 99 & 26,5 & 12,9 & 18,6 & 28,6 \\
\hline Junho - 99 & 26,8 & 12,9 & 18,6 & 19,9 \\
\hline
\end{tabular}

*A precipitação pluviométrica total no período foi de $1629,4 \mathrm{~mm}$.

Os parâmetros analisados na produção de massa verde por planta de amoreira foram: produção média de folhas por planta, produção média de ramos por planta. Enquanto que na produção de casulos, foram estudados o peso médio e teor líquido médio de seda casulos do bicho-da-seda.

Para se avaliar a produção de folhas e de ramos, aos 90 dias após a poda, foi coletada toda a parte aérea de 1 planta, ao acaso, de cada parcela. Os ramos foram pesados inteiros (com as folhas) e logo a seguir foram destacadas as folhas e pesados novamente somente os ramos. A determinação do peso de folhas por planta foi obtida pela diferença entre o peso dos ramos com folhas e sem folhas.

Para obter o peso médio dos casulos foram selecionados casualmente 30 casulos por parcela, os quais foram pesados, obtendo-se o seu peso médio (casulo cheio). Após a pesagem, cortaram-se os 30 casulos e retiraram-se as crisálidas e o espólio, os quais foram pesados, calculando-se o peso de 30 casulos vazios (sem crisálidas e espólio).

Para calcular o teor líquido de seda usou-se a seguinte fórmula: \% Seda bruta $=\{$ Peso de 30 casulos vazios (sem crisálida e espólio) / Peso de 30 casulos cheios (com crisálida e espólio)\} x 100. O teor líquido de seda foi obtido descontando-se $24 \%$ do teor de seda bruta, o qual corresponde a perda durante a industrialização do fio (Takahashi, 1994).

\section{RESULTADOS E DISCUSSÃO}

\section{Produção de massa verde por planta de amoreira:}

A produção de massa verde por planta de amoreira envolve a produção de folhas e produção de ramos pelas plantas. $\mathrm{Na}$ TABELA 2 são apresentados os valores para o F, o coeficiente de variação (C.V.) e a diferença mínima significativa (D.M.S.) na análise conjunta, obtidos pela análise de variância dos dois ensaios e da análise conjunta da produção média de folhas por planta de amoreira.

Observa-se que no $1^{\circ}$ ensaio não houve diferenças significativas nos blocos, nos híbridos e na interação, contudo houve efeitos significativos na adubação. No $2^{\circ}$ ensaio podemos observar que também não houve efeitos significativos nos blocos e na interação híbridos $x$ adubação, porém houve efeitos nos híbridos e na adubação. $\mathrm{Na}$ análise conjunta dos dados podemos observar mais uma vez que não houve efeitos significativos $(P>0,05)$ nos blocos e na interação híbrido $x$ adubação, mas houve efeitos significativos nos híbridos e na adubação.

Na TABELA 3 observa-se a produção média de folhas por planta de amoreira no $1^{\circ}$ e $2^{\circ}$ ensaios e na análise conjunta dos híbridos e dos tratamentos.

O híbrido IZ 56/4 apresentou maior produção de folhas/planta que os demais híbridos no $2^{\circ}$ ensaio e na análise conjunta. Os IZ 64 e IZ 19/13 não diferiram.

Em relação à adubação, no $1^{\circ}$ ensaio e na análise conjunta, as plantas que receberam o tratamento com matéria orgânica associada ao gesso agrícola $\left(T_{3}\right)$ produziram estatisticamente mais folhas/planta do que as dos tratamentos com matéria orgânica $\left(T_{2}\right)$ e testemunha $\left(T_{1}\right)$. As plantas do tratamento $T_{2}$ apresentaram maior produção de folhas/planta do que as do $T_{1}$. No $2^{\circ}$ ensaio, o $T_{3}$ não diferiu do $T_{2}$, contudo ambos produziram mais folhas do que as da testemunha $\left(T_{1}\right)$.

Os valores apresentados no $2^{\circ}$ ensaio mostram uma redução na produção de folha/planta em relação ao $1^{\circ}$ ensaio, isto pode estar ligado a dois fatores que podem ser observados na TABELA 1. A partir de março/ 1999 houve um decréscimo na precipitação pluviométrica, chegando a junho com aproximadamente $20 \mathrm{~mm}$ de chuvas. Além disto, as temperaturas também foram diminuindo, e como a amoreira é uma planta caducifólia no período de inverno, a planta começou a se preparar para este período, promovendo um amarelecimento e senescência de algumas folhas. 
A produção de folhas é um dos parâmetros mais importantes para a sericicultura, pois através dele podemos inferir a quantidade de lagarta do bicho-daseda que poderá ser criada em uma determinada área. Nos resultados da análise conjunta, se fosse dado um índice relativo de $100 \%$ ao híbrido IZ 64, o IZ 56/4 teria uma produção de folhas $27 \%$ maior do que ele. Admitindo-se um valor de $100 \%$ para a testemunha, a produção de folhas das plantas adubadas com matéria orgânica associada ao gesso agrícola seria $102 \%$ maior e a adubação com matéria orgânica seria $44 \%$ maior que a testemunha, mas se aplicássemos os mesmos $100 \%$ para a adubação com matéria orgânica, a influência do gesso agrícola aumentaria a produção de folhas em $40 \%$. Isto mostra que a criação do bicho-da-seda poderia ser aumentada em $27 \%$ somente pela utilização do IZ $56 / 4$ ao invés do IZ 64 e que se fosse realizada uma adubação com matéria orgânica associada ao gesso agrícola, poderia ter um aumento na criação do bicho-da-seda em até $102 \%$ utilizando uma mesma área de amoreira.

$\mathrm{Na}$ TABELA 4 são apresentados os valores para o $\mathrm{F}$, o coeficiente de variação (C.V.) e a diferença mínima significativa (D.M.S.), obtidos pela análise de variância dos dois ensaios e da análise conjunta da produção média de ramos por planta de amoreira.

A análise de variância mostrou que no $1^{\circ}$ ensaio não houve efeitos significativos nos blocos e nos híbridos, contudo houve efeitos significativos na adubação. No $2^{\circ}$ ensaio e na análise conjunta houveram efeitos significativos nos híbridos e na adubação $(P<0,05)$. Nos dois ensaios e na análise conjunta não houve efeitos significativos na interação híbridos $x$ adubação.

Na TABELA 5 observa-se a produção média de ramos por planta de amoreira no $1^{\circ}$ e $2^{\circ}$ ensaios e na análise conjunta dos híbridos e dos tratamentos.

Na produção de ramos/planta podemos verificar que no $2^{\circ}$ ensaio e na análise conjunta, o IZ 56/4 obteve maior produção que o IZ 19/13. No $2^{\circ}$ ensaio, o IZ 56/4 foi superior também ao IZ 64 .

$\mathrm{Na}$ adubação observamos que o tratamento $T_{3}$ apresentou estatisticamente mais ramos/planta que as do $T_{2}$ e $T_{1}$ no $1^{\circ}$ ensaio e na análise conjunta e que as plantas do tratamento $T_{2}$ tiveram uma produção estatisticamente maior que as do $T_{1}$. No $2^{\circ}$ ensaio, a testemunha $\left(T_{1}\right)$ apresentou produção de ramos/planta estatisticamente inferior em relação aos outros dois tratamentos $\left(T_{2}\right.$ e $\left.T_{3}\right)$.

Em trabalho desenvolvido por Takahashi (1988) a amoreira da variedade Miura com mais de 8 anos de plantio, adubada com $2 \mathrm{~kg}$ de esterco de galinha/planta/ corte produziu 1,67 kg de folhas/planta/corte e 1,93 kg de ramos/planta/corte. Os valores encontrados na presente pesquisa estão abaixo dos encontrados por Takahashi (1988), principalmente porque as plantas, embora sendo híbridas, possuem apenas 3 anos de plantio.
Marincek (1995) estudando a influência de diferentes tipos de adubação orgânica de origem animal na produção da amoreira, fez incorporação de $2 \mathrm{~kg}$ de esterco/planta. Os valores encontrados para a produção de folhas/planta que receberam adubação com esterco

TABELA 2 - Valores de F, coeficiente de variação (cv.) e diferença mínima significativa (D.M.S.) no $1^{\circ} \mathrm{e}$ $2^{\circ}$ ensaios e na análise conjunta, obtidos pela análise de variância da produção de folhas por planta de amoreira.

\begin{tabular}{lccc}
\hline $\begin{array}{l}\text { Parâmetros } \\
\text { Estatísticos }\end{array}$ & $1^{\circ}$ ensaio & $2^{\circ}$ ensaio & $\begin{array}{c}\text { Análise } \\
\text { Conjunta }\end{array}$ \\
\hline Blocos & $3,01^{\text {ns }}$ & $0,67^{\text {ns }}$ & $3,18^{\text {ns }}$ \\
Híbridos & $1,90^{\text {ns }}$ & $12,50^{* *}$ & $10,94^{* *}$ \\
Adubação & $32,01^{* *}$ & $13,45^{* *}$ & $46,72^{* *}$ \\
Híbridos x & $2,17^{\text {ns }}$ & $1,32^{\text {ns }}$ & $3,09^{\text {ns }}$ \\
Adubação & 22,19 & 23,65 & 15,11 \\
\hline C.V. (\%) & 0,1925 & 0,1226 & 0,111 \\
\hline DMS (\%) & &
\end{tabular}

ns = não significativo $e^{* *}=$ significativo a $5 \%$

TABELA 3 - Produção média de folhas por planta de amoreira no $1^{\circ}$ e $2^{\circ}$ ensaios e na análise conjunta dos híbridos e dos tratamentos.

\begin{tabular}{lccc}
\hline Híbridos & $1^{\circ}$ Ensaio & $2^{\circ}$ Ensaio & Análise Conjunta \\
\hline & $0,92 \mathrm{~A}$ & $0,49 \mathrm{~B}$ & $0,70 \mathrm{~B}$ \\
$\mathrm{Z} 64$ & $0,97 \mathrm{~A}$ & $0,52 \mathrm{~B}$ & $0,72 \mathrm{~B}$ \\
$\mathrm{IZ} 19 / 13$ & $1,05 \mathrm{~A}$ & $0,72 \mathrm{~A}$ & $0,89 \mathrm{~A}$ \\
$\mathrm{Z}_{56 / 4}$ & $0,66 \mathrm{C}$ & $0,42 \mathrm{~b}$ & $0,57 \mathrm{C}$ \\
$\mathrm{T}_{1}$ & $0,94 \mathrm{~b}$ & $0,64 \mathrm{a}$ & $0,82 \mathrm{~b}$ \\
$\mathrm{~T}_{2}$ & $1,29 \mathrm{a}$ & $0,66 \mathrm{a}$ & $1,15 \mathrm{a}$ \\
$\mathrm{T}_{3}$ &
\end{tabular}

As médias, na mesma coluna, seguidas por letras maiúsculas, referem-se ao efeito dos híbridos e as médias, na mesma coluna, seguidas por letras minúsculas referem-se ao efeito da adubação. Letras iguais não diferem estatisticamente $(P>0,05)$.

$\mathrm{T}_{1}$ - testemunha; $\mathrm{T}_{2}$ - Adubação com matéria orgânica e $\mathrm{T}_{3}$ - Adubação com matéria orgânica associada a gesso agrícola.

TABELA 4 - Valores de F, coeficiente de variação (cv.) e diferença mínima significativa (D.M.S.) no $1^{\circ} \mathrm{e}$ $2^{\circ}$ ensaios e na análise conjunta, obtidos pela análise de variância da produção média de ramos por planta de amoreira.

\begin{tabular}{lccc}
\hline \multicolumn{1}{c}{$\begin{array}{c}\text { Parâmetros } \\
\text { Estatísticos }\end{array}$} & $1^{\circ}$ ensaio & $\begin{array}{c}2^{\circ} \\
\text { ensaio }\end{array}$ & $\begin{array}{c}\text { Análise } \\
\text { Conjunta }\end{array}$ \\
\hline Blocos & $2,21^{\text {ns }}$ & $0,77^{\text {ns }}$ & $2,65^{\text {ns }}$ \\
Híbridos & $1,42^{\text {ns }}$ & $16,49^{* *}$ & $3,63^{* *}$ \\
Adubação & $29,02^{* *}$ & $17,42^{* *}$ & $44,49^{* *}$ \\
Híbridos x & $1,29^{\text {ns }}$ & $1,21^{\text {ns }}$ & $1,75^{\text {ns }}$ \\
Adubação & 24,85 & 24,93 & 17,09 \\
\hline C.V. (\%) & 0,189 & 0,0859 & 0,103 \\
\hline DMS (\%) & &
\end{tabular}

${ }^{n s}=$ não significativo $e^{* *}=$ significativo a $5 \%$ 
TABELA 5 - Produção média de ramos por planta de amoreira no $1^{\circ}$ e $2^{\circ}$ ensaios e na análise conjunta dos híbridos e dos tratamentos.

\begin{tabular}{lccc}
\hline $\begin{array}{c}\text { Híbridos/ } \\
\text { Tratamentos }\end{array}$ & $1^{\circ}$ Ensaio & $2^{\circ}$ Ensaio & $\begin{array}{c}\text { Análise } \\
\text { Conjunta }\end{array}$ \\
\hline I 64 & $0,92 \mathrm{~A}$ & $0,36 \mathrm{~B}$ & $0,64 \mathrm{AB}$ \\
$\mathrm{IZ} \mathrm{19/13}$ & $0,80 \mathrm{~A}$ & $0,29 \mathrm{~B}$ & $0,55 \mathrm{~B}$ \\
$\mathrm{Z} 56 / 4$ & $0,82 \mathrm{~A}$ & $0,49 \mathrm{~A}$ & $0,66 \mathrm{~A}$ \\
$\mathrm{~T}_{1}$ & $0,57 \mathrm{C}$ & $0,27 \mathrm{~b}$ & $0,42 \mathrm{C}$ \\
$\mathrm{T}_{2}$ & $0,82 \mathrm{~b}$ & $0,43 \mathrm{a}$ & $0,63 \mathrm{~b}$ \\
$\mathrm{~T}_{3}$ & $1,15 \mathrm{a}$ & $0,46 \mathrm{a}$ & $0,81 \mathrm{a}$ \\
\hline
\end{tabular}

As médias, na mesma coluna, seguidas por letras maiúsculas, referem-se ao efeito dos híbridos e as médias, na mesma coluna, seguidas por letras minúsculas referem-se ao efeito da adubação. Letras iguais não diferem estatisticamente a $(P>0,05)$.

$T_{1}$ - testemunha; $T_{2}$ - Adubação com matéria orgânica.

$\mathrm{T}_{3}$ - Adubação com matéria orgânica associada a gesso agrícola.

de aves $(1,812 \mathrm{~kg}$ de folhas/planta) foram maiores aos encontrados nesta pesquisa, contudo tanto naquela quanto nesta pesquisa, podemos concluir que a incorporação de esterco de aves (galinha) promove um aumento na produção de folhas da amoreira em relação às plantas que não receberam adubação (testemunha), mostrando assim a importância da adubação orgânica para a amoreira.

Bellizzi (1997) estudando o efeito do calcário e do gesso agrícola associado à adubação com NPK e micronutrientes, encontrou para o peso médio dos ramos (em kg/planta) que a adubação com gesso agrícola + NPK foi estatisticamente superior a todos os tratamentos. $\mathrm{Na}$ presente pesquisa o gesso agrícola associado a matéria orgânica influenciou positivamente na produção de ramos pela amoreira, indicando que a associação do gesso agrícola com a adubação orgânica ou química é benéfica à planta.

\section{Produção de casulos do bicho-da-seda}

A TABELA 6 apresenta os valores de $F$, coeficiente de variação (c.v.) e diferença mínima significativa (D.M.S.) obtidos de análise de variância dos dois ensaios e da análise conjunta do peso médio do casulo do bicho-da-seda.

No $1^{\circ}$ ensaio foram encontrados efeitos significativos dos blocos, nos híbridos, na adubação e na interação híbridos $x$ adubação. No $2^{\circ}$ ensaio, assim como na análise conjunta, não foram encontrados efeitos nos blocos e nem na interação híbridos x adubação, contudo foram observados efeitos significativos nos híbridos e na adubação.

$\mathrm{Na}$ TABELA 7 encontram-se os valores do peso médio $(\mathrm{g})$ do casulo do bicho-da-seda no $1^{\circ}$ e $2^{\circ}$ ensaios e na análise conjunta dos híbridos e dos tratamentos.

Podemos observar que os casulos produzidos pelas lagartas alimentadas com folhas do IZ 56/4 foram estatisticamente mais pesados do que aqueles produzidos pelas lagartas dos outros dois híbridos nos dois ensaios e na análise conjunta. No $1^{\circ}$ ensaio e na análise conjunta, os casulos das lagartas alimentadas com o IZ 19/13 foram mais pesados do que os do híbridos IZ 64

No $2^{\circ}$ ensaio e na análise conjunta os casulos produzidos pelas lagartas alimentadas com folhas que receberam adubação com matéria orgânica associada a gesso agrícola $\left(T_{3}\right)$ foram mais pesados do que os produzidos pelas lagartas do $T_{2}$ (matéria orgânica).

Nos $1^{\circ}$ e $2^{\circ}$ ensaios e na análise conjunta, os casulos produzidos pelas lagartas que receberam folhas da testemunha $\left(T_{1}\right)$ foram estatisticamente mais leves do que os produzidos no $T_{2}$ e no $T_{3}$, mostrando que a adubação com matéria orgânica influencia no peso dos casulos.

Nesta pesquisa, se admitirmos o índice de $100 \%$ para o peso dos casulos produzidos pelas lagartas alimentadas com o IZ 64, na análise conjunta, o peso dos casulos obtidos com o IZ 19/13 é 3,63\% maior e o IZ 56/4 é 7,29\% mais pesados do que os produzidos no IZ 64. Em termos de adubação, admitindo-se $100 \%$ para os casulos obtidos pelas lagartas da testemunha, os produzidos no tratamento com matéria orgânica $\left(T_{2}\right)$ foi de $4,73 \%$ maior e no tratamento com matéria orgânica associada ao gesso agrícola $\left(T_{3}\right)$ foi de $9,47 \%$ maior que os da testemunha. Este valores nos levam a pensar que quando formos implantar um amoreiral, a escolha de um híbrido de amoreira e a sua adubação com matéria orgânica com gesso agrícola podem aumentar significativamente a rentabilidade da sericicultura.

A influência dos cultivares no peso dos casulos foi observada por Paolieri \& Frota (1970), Hirano (1982) e Takahashi et. al. (1987), os quais verificaram a influência direta dos cultivares no peso dos casulos.

A produção de casulos mais pesados e o teor de seda mais elevado são fatores que influenciam diretamente na rentabilidade da exploração, pois quanto mais pesado for o casulo, maior será a quantidade a ser comercializada e se o teor de seda também for elevado (acima de 17\%), maior será o preço do casulo, aumentando assim o lucro do sericicultor (Takahashi, 1996).

A TABELA 8 apresenta os valores de F, coeficiente de variação (c.v.) e diferença mínima significativa (D.M.S.) obtidos de análise de variância do teor líquido médio de seda dos casulos do bicho-daseda.

No $1^{\circ}$ ensaio foram encontrados efeitos significativos nos híbridos. No $2^{\circ}$ ensaio não foram encontrados efeitos nos blocos e nem na interação híbridos $x$ adubação, contudo foram observados efeitos significativos nos híbridos e na adubação. $\mathrm{Na}$ análise conjunta foram encontrados efeitos nos blocos, nos híbridos e na adubação. 
Na TABELA 9 observamos os valores do teor líquido médio (\%) de seda dos casulos do bicho-da-seda no $1^{\circ}$ e $2^{\circ}$ ensaios e na análise conjunta dos híbridos e dos tratamentos.

O teor líquido de seda nos casulos dos híbridos IZ 56/4 e IZ 64 no $1^{\circ}$ ensaio e na análise conjunta foram superiores aos do IZ 19/13 e no $2^{\circ}$ ensaio os casulos

TABELA 6 - Valores de F, coeficiente de variação (cv.) e diferença mínima significativa (D.M.S.) no $1^{\circ} \mathrm{e}$ $2^{\circ}$ ensaios e na análise conjunta, obtidos pela análise de variância do peso médio do casulo de bicho-da-seda.

\begin{tabular}{|c|c|c|c|}
\hline $\begin{array}{l}\text { Parâmetros } \\
\text { Estatísticos }\end{array}$ & $1^{\circ}$ ensaio & $2^{\circ}$ ensaio & $\begin{array}{l}\text { Análise } \\
\text { Conjunta }\end{array}$ \\
\hline & \multicolumn{3}{|c|}{ 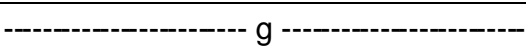 } \\
\hline Blocos & $3,35^{\star *}$ & $1,32^{\text {ns }}$ & $1,67^{\text {ns }}$ \\
\hline Híbridos & $22,89^{\star *}$ & $34,02^{* *}$ & $25,14^{* *}$ \\
\hline Adubação & $11,13^{\star *}$ & $39,35^{\star *}$ & $39,04^{\star *}$ \\
\hline $\begin{array}{l}\text { Híbridos x } \\
\text { Adubação }\end{array}$ & $2,00^{* *}$ & $1,36 \mathrm{~ns}$ & $2,20^{\text {ns }}$ \\
\hline C.V. (\%) & 3,36 & 3,60 & 2,71 \\
\hline DMS (\%) & 0,0565 & 0,0683 & 0,0486 \\
\hline
\end{tabular}

${ }^{\mathrm{ns}}=$ não significativo $\mathrm{e}^{* *}=$ significativo a $5 \%$

TABELA 7 - Peso médio do casulo do bicho-da-seda no $1^{\circ} \mathrm{e}$ $2^{\circ}$ ensaios e na análise conjunta dos híbridos e dos tratamentos.

\begin{tabular}{lccc}
\hline $\begin{array}{c}\text { Hibrido } \\
\text { Tratamentos }\end{array}$ & $1^{\circ}$ Ensaio & $2^{\circ}$ Ensaio & $\begin{array}{c}\text { Análise } \\
\text { Conjunta }\end{array}$ \\
\hline $\mathrm{Z} 64$ & $1,78 \mathrm{C}$ & $2,06 \mathrm{~B}$ & $1,92 \mathrm{C}$ \\
$\mathrm{IZ} 19 / 13$ & $1,88 \mathrm{~B}$ & $2,03 \mathrm{~B}$ & $1,99 \mathrm{~B}$ \\
$\mathrm{Z}_{56 / 4}$ & $1,94 \mathrm{~A}$ & $2,24 \mathrm{~A}$ & $2,06 \mathrm{~A}$ \\
$\mathrm{~T}_{1}$ & $1,81 \mathrm{~b}$ & $2,00 \mathrm{C}$ & $1,90 \mathrm{C}$ \\
$\mathrm{T}_{2}$ & $1,89 \mathrm{a}$ & $2,09 \mathrm{~b}$ & $1,99 \mathrm{~b}$ \\
$\mathrm{~T}_{3}$ & $1,91 \mathrm{a}$ & $2,24 \mathrm{a}$ & $2,08 \mathrm{a}$ \\
\hline
\end{tabular}

As médias, na mesma coluna, seguidas por letras maiúsculas, referem-se ao efeito dos híbridos e as médias, na mesma coluna, seguidas por letras minúsculas referem-se ao efeito da adubação. Letras iguais não diferem estatisticamente a $(P>0,05)$.

$T_{1}$ - testemunha; $T_{2}$ - Adubação com matéria orgânica e $T_{3}$ - Adubação com matéria orgânica associada a gesso agrícola.

TABELA 8 - Valores de F, coeficiente de variação (C.V.) e diferença mínima significativa (D.M.S.) no $1^{\circ} \mathrm{e}$ $2^{\circ}$ ensaios e na análise conjunta, obtidos pela análise de variância do teor líquido médio de seda dos casulos do bicho-da-seda.

\begin{tabular}{|c|c|c|c|}
\hline $\begin{array}{l}\text { Parâmetros } \\
\text { Estatísticos }\end{array}$ & $\begin{array}{c}1^{\circ} \\
\text { ensaio }\end{array}$ & $\begin{array}{c}2^{\circ} \\
\text { ensaio }\end{array}$ & $\begin{array}{l}\text { Análise } \\
\text { Conjunta }\end{array}$ \\
\hline Blocos & $1,65^{\text {ns }}$ & $1,40^{\text {ns }}$ & $2,85^{\star \star}$ \\
\hline Híbridos & $6,94^{\star \star}$ & $3,37^{\star *}$ & $8,01^{* *}$ \\
\hline Adubação & $1,19^{\text {ns }}$ & $6,45^{\star *}$ & $3,35^{\star *}$ \\
\hline $\begin{array}{l}\text { Híbridos x } \\
\text { Adubação }\end{array}$ & $1,85^{\text {ns }}$ & $2,01^{\mathrm{ns}}$ & $1,22^{\mathrm{ns}}$ \\
\hline C.V. (\%) & 3,19 & 3,88 & 2,52 \\
\hline DMS (\%) & 0,5007 & 0,6127 & 0,3969 \\
\hline
\end{tabular}

Scientia Agricola, v.58, n.2, p.349-355, abr./jun. 2001 do IZ 56/4 apresentaram maior teor líquido de seda que os casulos do IZ 19/13.

Em relação a adubação, no $2^{\circ}$ ensaio, o teor líquido de seda nos casulos do $\mathrm{T}_{2}$ foram estatisticamente superiores aos do $T_{1}$ e $T_{3}$ e na análise conjunta, os casulos do $\mathrm{T}_{2}$ obtiveram teor líquido de seda maior do que os do $T_{3}$.

Toledo (1996) estudando a influência de diferentes manejos de alimentação (M1 - trato alimentar a cada 6 horas, M2 - trato alimentar a cada 4 horas e M3 - trato alimentar a cada 2 horas), em três diferentes ambientes com variação da temperatura (A1 temperatura natural, $\mathrm{A} 2$ - aquecido das 18:00 às 06:00 horas e A3 - aquecido 24 horas), utilizando a variedade Miura, encontrou para o peso médio dos casulos, no $A 1$, valores de 1,$807 ; 1,841$ e $1,857 \mathrm{~g}$. No $A 2$, valores de 1,$637 ; 1,685$ e $1,876 \mathrm{~g}$. No $A 3$, valores de 1,563; 1,620 e $1,767 \mathrm{~g}$, respectivamente no M1, M2 e M3. Para o teor líquido de seda, no $\mathrm{A} 1$, no $\mathrm{M} 1=15,57 \%$; no $\mathrm{M} 2$ $=15,65 \%$ e no $M 3=15,71 \%$. No $A 2$, no $M 1=16,49 \%$; no $M 2=16,70 \%$ e no $M 3=16,96 \%$. No $A 3$, no $M 1=$ $18,22 \%$; no $M 2=18,81 \%$ e no $M 3=18,88 \%$. Comparativamente podemos observar que uma boa nutrição do bicho-da-seda, com folhas de alta qualidade influencia mais do que um manejo de alimentação adequado, estando ambos em condições ambientais favoráveis ao bicho-da-seda, isto é com temperatura entre 22 a $25^{\circ} \mathrm{C}$ e umidade relativa entre 60 a $90 \%$ (de acordo com o ínstar).

Estudando o peso dos casulos das lagartas do bicho-da-seda alimentadas com folhas de híbridos e de uma variedade de amoreira, Mendonça (1994) encontrou que os híbridos IZ 19/13 (2,29 g) e IZ 56/4 (2,30 g) foram estatisticamente superiores ao híbrido IZ 64 (2,00 g). Para o teor de seda, valores que variaram de $17,15 \%$ a 17,77\% e que o híbrido IZ 64 apresentou o menor teor de seda. Estes valores se aproximam dos encontrados nesta pesquisa, embora sendo o híbrido IZ 19/13 que apresentou menor teor de seda nesta pesquisa.

TABELA 9 - Teor líquido médio de seda dos casulos do bichoda-seda no $1^{\circ}$ e $2^{\circ}$ ensaios e na análise conjunta dos híbridos e dos tratamentos.

\begin{tabular}{lccc}
\hline $\begin{array}{c}\text { Hibrido } \\
\text { Tratamentos }\end{array}$ & $1^{\circ}$ Ensaio & $2^{\circ}$ Ensaio & $\begin{array}{c}\text { Análise } \\
\text { Conjunta }\end{array}$ \\
\hline $\mathrm{Z} 64$ & ------------ \\
$\mathrm{IZ} \mathrm{19/13}$ & $17,78 \mathrm{~A}$ & $17,55 \mathrm{AB}$ & $17,67 \mathrm{~A}$ \\
$\mathrm{Z}$ 56/4 & $17,05 \mathrm{~B}$ & $17,26 \mathrm{~B}$ & $17,16 \mathrm{~B}$ \\
$\mathrm{~T}_{1}$ & $17,60 \mathrm{~A}$ & $17,90 \mathrm{~A}$ & $17,76 \mathrm{~A}$ \\
$\mathrm{~T}_{2}$ & $17,66 \mathrm{a}$ & $17,41 \mathrm{~b}$ & $17,54 \mathrm{ab}$ \\
$\mathrm{T}_{3}$ & $17,38 \mathrm{a}$ & $18,08 \mathrm{a}$ & $17,73 \mathrm{a}$ \\
\hline
\end{tabular}

As médias, na mesma coluna, seguidas por letras maiúsculas, referem-se ao efeito dos híbridos e as médias, na mesma coluna, seguidas por letras minúsculas referem-se ao efeito da adubação. Letras iguais não diferem estatisticamente a $(P>0,05)$.

$T_{1}$ - testemunha; $T_{2}$ - Adubação com matéria orgânica e $T_{3}$ - Adubação com matéria orgânica associada a gesso agrícola. 


\section{AGRADECIMENTOS}

À Fiação de Seda Bratac S.A., à Bonifácio Bellizzi pelo auxílio na condução do experimento e ao $\mathrm{CNPq}$ pelo suporte financeiro.

\section{REFERÊNCIAS BIBLIOGRÁFICAS}

ABREU, O.C.; ABRAMIDES, P. Técnica de cultura da amoreira Morus alba L. Campinas: CATI, 1976. 24p. (Boletim Técnico, 2).

BELLIZZI, N.C. Efeito do calcário e gesso agrícola associados a adubação com NPK e micronutrientes na amoreira (Morus alba, L.) e o bicho-da-seda (Bombyx mori, L.). Jaboticabal, 1997. 113p. Dissertação (Mestrado) - Faculdade de Ciências Agrárias e Veterinárias, Universidade Estadual Paulista "Júlio de Mesquita Filho".

FONSECA, A.S.; FONSECA, T.C. Cultura da amoreira e criação do bicho-da-seda. São Paulo: Nobel, 1988. 246p.

FONSECA, T.C.; ALMEIDA, J.E.; OKAMOTO, F. Le programme d'amelioration du murrier dons l'etil de São Paulo Brasil. Sericologia, v.34, p.727-733, 1994.

GOMIDE, J.T.B.; TAKAHASHI, R. Efeito da adubação nitrogenada na produção da amoreira e sua influência na produção de casulos do bicho-da-seda (Bombyx mori, L). Ciência Zootecnica, v.2, p.5-6, 1987.

HIRANO, $\mathrm{H}$. Varieted difference of leaf protein profiles in mulberry. Journal of the Sericultural Science of Japan, v.21, p.36-41,1982.

MARINCEK, S.P. Efeitos de diferentes tipos de adubação orgânica na amoreira (Morus alba L.). Jaboticabal, 1995. 29p. Monografia (Graduação) - Faculdade de Ciências Agrárias e Veterinárias, Universidade Estadual Paulista "Júlio de Mesquita Filho".

MENDONÇA, G.A. Utilização de híbridos de amoreira na produção de casulos de bicho-da-seda (Bombyx mori L.). Piracicaba, 1994. 59p. Dissertação (Mestrado) - Escola Superior de Agricultura "Luiz de Queiroz", Universidade de São Paulo.

PAOLIERI, L.; FROTA, A. Competição de variedades de amoreira. Campinas: Serviço de Sericicultura, 1970. 16p. (Boletim Técnico Sericícola, 57).
RUBIA, A.C. Variedades de amoreira e seu emprego na criação do bicho-da-seda. Revista de Agricultura, v.39, p.83-87, 1964.

RUBIA, A.C.; ABRAMIDES, E. Resultados preliminares de ensaio das variedades $x$ espaçamentos $x$ épocas de poda em amoreira no sistema cepo. Revista de Agricultura, v.40, p.56-62, 1965.

RUBIA, A.C.; PETTINELI, A.; ABRAMIDES, E. Produção de folhas de diferentes variedades de amoreira durante o período de formação das mudas nos sistemas de cepo e fuste. Bragantia, v.25, p.203-209, 1966.

SOUSA, D.M.G.; LOBATO, E.; REIN, T.A. Uso de gesso agrícola nos solos do cerrado. Planaltina: EMBRAPA, CPAC, 1995. 20p. (Circular Técnica, 32).

TAKAHASHI, R. Efeito dos diferentes tipos de adubação na produção de amoreira (Morus alba, L.) sua influencia no desenvolvimento da glândula sericígena e na produção de casulos do bicho-da-seda. (Bombyx mori, L.). Rio Claro, 1988. 186p. Tese (Doutorado) - Instituto de Biociências, Universidade Estadual Paulista "Júlio de Mesquita Filho".

TAKAHASHI, R. Sericicultura. Jaboticabal: UNESP, FCAV, 1994. 135p.

TAKAHASHI, R. Características vegetativas e nutricionais de cultivares de amoreira utilizados na alimentação do bichoda-seda (Bombyx mori L.) (Lepidoptera: Bombycidae). Jaboticabal, 1996. 118p. Tese (Livre Docência) - Faculdade de Ciências Agrárias e Veterinárias, Universidade Estadual Paulista "Júlio de Mesquita Filho".

TAKAHASHI, R.; KRONKA, S.N.; KRONKA, R.N. Influência da variedade da amoreira na produção de casulos do bicho-daseda na primavera, verão e outono. Zootecnia, v.25, p.77-84, 1987.

TOLEDO, J.O.A. Eficiência da utilização do alimento e desempenho do bicho-da-seda (Bombyx mori L.), sob diferentes temperaturas e em três manejos de alimentação. Jaboticabal, 1996. 118p. Tese (Doutorado) - Faculdade de Ciências Agrárias e Veterinárias, Universidade Estadual Paulista "Júlio de Mesquita Filho".

$\overline{\text { Recebido em } 15.03 .00}$ 